\title{
New monitoring technique for rapid investigation of nitrates pollution in aquatic systems
}

\author{
MARIA CRISTINA TRIFU \& VALERIA DARADICI \\ National Institute of Hydrology and Water Management, Sos. Bucuresti-Ploiesti, no. 97, cod 01686, Bucharest, Romania \\ cris.trifu@hidro.ro
}

\begin{abstract}
In situ measurement with a portable multi-parameter sonde was used in the framework of the Cleanwater project - LIFE09 ENV/RO/000612, for a rapid investigation of nitrates pollution in Barlad River basin, in rivers and domestic wells, in addition to laboratory measurements. Water samples were analysed in an accredited laboratory for water monitoring, such as the Vaslui Water Management System from Barlad basin. Sampling campaigns were performed monthly in the period April-November 2011. In order to find the main factors that influence the measurements, the behaviour of equipment was analysed in rivers, for different water sampling points along the river and the cross-sections, taking into account the water level, the turbulence, the vegetation and the obstacles along the river. Results proved the multiparameter sonde as a useful device for rapidly monitoring spatial distributions or temporal trends of nitrates or chlorophyll $a$, and detecting sudden changes in surface and groundwater quality.
\end{abstract}

Key words portable sonde, nitrates, monitoring, rivers

\section{INTRODUCTION}

This paper is the presentation of the field campaigns accomplished in the framework of the Cleanwater Project (LIFE09 ENV/RO/000612). At European Union level a number of legal documents to protect and improve the sustainable management of water resources have been developed. One of the documents is Directive 91/676/EEC concerning the protection of waters against pollution caused by nitrates from agricultural sources (Nitrates Directive) which has as main objectives the reduction of pollution caused or induced by nitrates from agricultural sources and prevention of water pollution with nitrates. As a result of the Water Framework Directive it has become necessary to monitor all water resources within a catchment.

The permanent knowledge of water resources status is an objective requirement which cannot be adequately achieved without a modern integrated water monitoring system. In Romania, the Water Monitoring System has been operating in a scientific and definite structure, but since 2002 the question of the modernization and the development of an integrated water monitoring system was raised so it could meet the European standards and the monitoring requirements (Dascalatia 2011).

The use of portable sonde equipment is increasingly, and seen as a big benefit for in situ measurements, as they provide rapid information and will miss no quality changes. These instruments have been available since the early 1970s and are deployed all over the world to monitor water quality in a wide variety of applications including groundwater, rivers, lakes, streams, reservoirs, marine water, mainly focusing on monitoring nitrates, ammonium and chlorophyll a (Mihajlovic et al. 2013).

\section{STUDY AREA}

The Barlad River, left bank tributary of the Siret River, is considered one of the large rivers in the country (Barlad Basin: surface of $7220 \mathrm{~km}^{2}$, mean altitude $211 \mathrm{~m}$ ) and from a total of $207 \mathrm{~km}$ length, the last $116 \mathrm{~km}$ are presented as being "at ecological risk" from the nutrients pollution point of view. Agricultural activities and the private households, throughout the basin, play a large part in the output of nitrogen and phosphorous concentrations. The land cover is based on: $46 \%$ arable land, $27 \%$ forests and $16.1 \%$ prairies. Annual average water debits on Barlad River increase from $2.37 \mathrm{~m}^{3} / \mathrm{s}$ at Vaslui city to $9.01 \mathrm{~m}^{3} / \mathrm{s}$ at Tecuci city. Almost $92 \%$ of the study area is nonirrigated arable land.

The studied area (Fig. 1) includes counties with low economic potential, such as Vaslui county that is considered one of the poorest counties in the country, where the main activity of the 
population is still agriculture, crop cultivation and livestock breeding, the sewage systems for waste waters being insufficiently developed (Breaban and Paiu 2012). Then growth in population during the communist regime and agricultural activities tends to result in groundwater pollution in rural area. One of the pollutants with high health risks is the nitrates, which occur in drinking water from many sources. High values of nitrate concentration in drinking water wells are due to the heavy use of fertilizers in agriculture, the affected area being situated near agricultural land (Macalet et al. 2008). Also in the area where the polluted wells are located, the sewage system is missing, which causes infiltration of wastewater loaded in organic compounds to the groundwater.

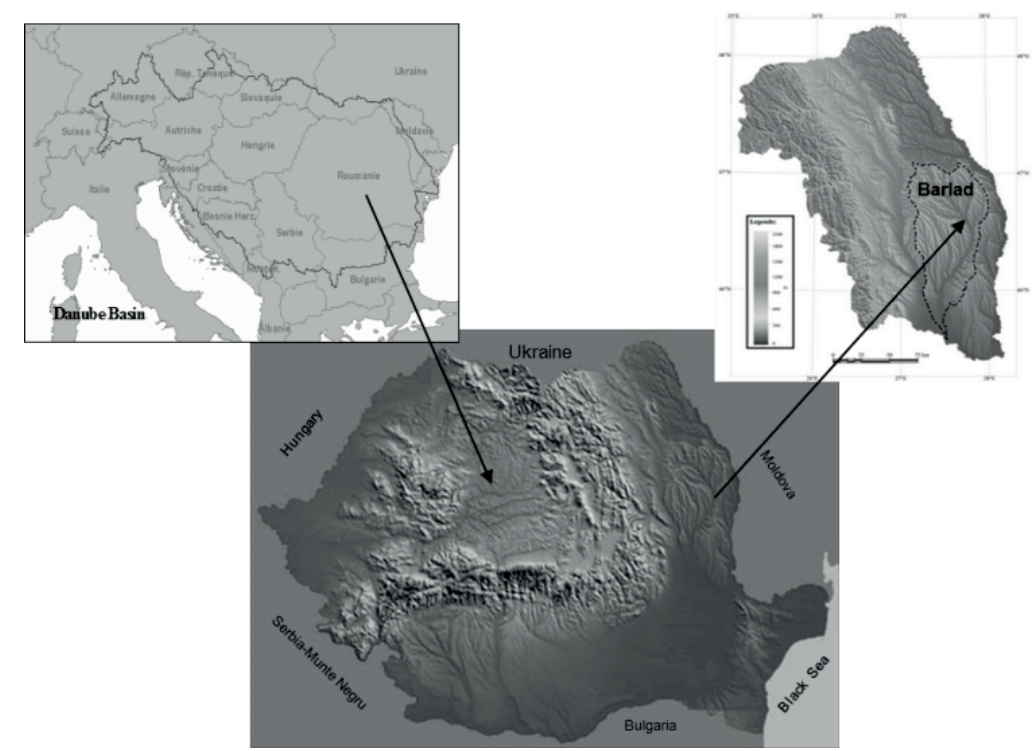

Fig. 1 Study area: Barlad River basin.

\section{METHODS}

A particular problem in the case of surface water quality monitoring is the complexity associated with collecting a large number of samples. Monitoring of water quality can be performed using different approaches such as fixed monitoring system and laboratory analyses, or sampling with portable devices and post analysis (Tuna et al. 2013).

In the framework of the CLEANWATER project, two field campaigns in summer and autumn were organized in more than 300 domestic wells (Trifu et al. 2012), in order to analyse: (i) the discontinuity of the designated nitrate vulnerable zones; (ii) the nitrate concentrations in the area situated near to designated vulnerable zones, and (iii) the influence of landscape, soil and local conditions on the nitrate level. In the analysed area there are no hydrological drills. However, along the main axis of the Barlad River we have performed monthly sampling campaigns (two samplings/month) in order to complete the values obtained in the national water monitoring system (Fig. 2). The measurements were performed in the control sections from the monitoring network, almost in the same location as the laboratory sampling.

The measurements have been done using the portable equipment water quality multi-probe sondes for in situ campaigns. The following parameters have been measured simultaneously: temperature, $\mathrm{pH}$, conductivity, dissolved oxygen and groundwater depth within the domestic wells, turbidity, $\mathrm{NO}_{3}, \mathrm{NH}_{4}$ and chlorophyll $a$. The portable equipment is based on the measurement of fluorescence using a submersible fluor-meter included into a specific sensor, which is incorporated in the multi-parameter sonde. To assure the accuracy of the portable device, the calibration of the apparatus was necessary every time, before or during the field campaigns.

Using the portable device there was the possibility of covering a large surveyed area in a short time, the main advantage being the simultaneous measurement, continuous and almost instantaneous measurement of the above parameters. 

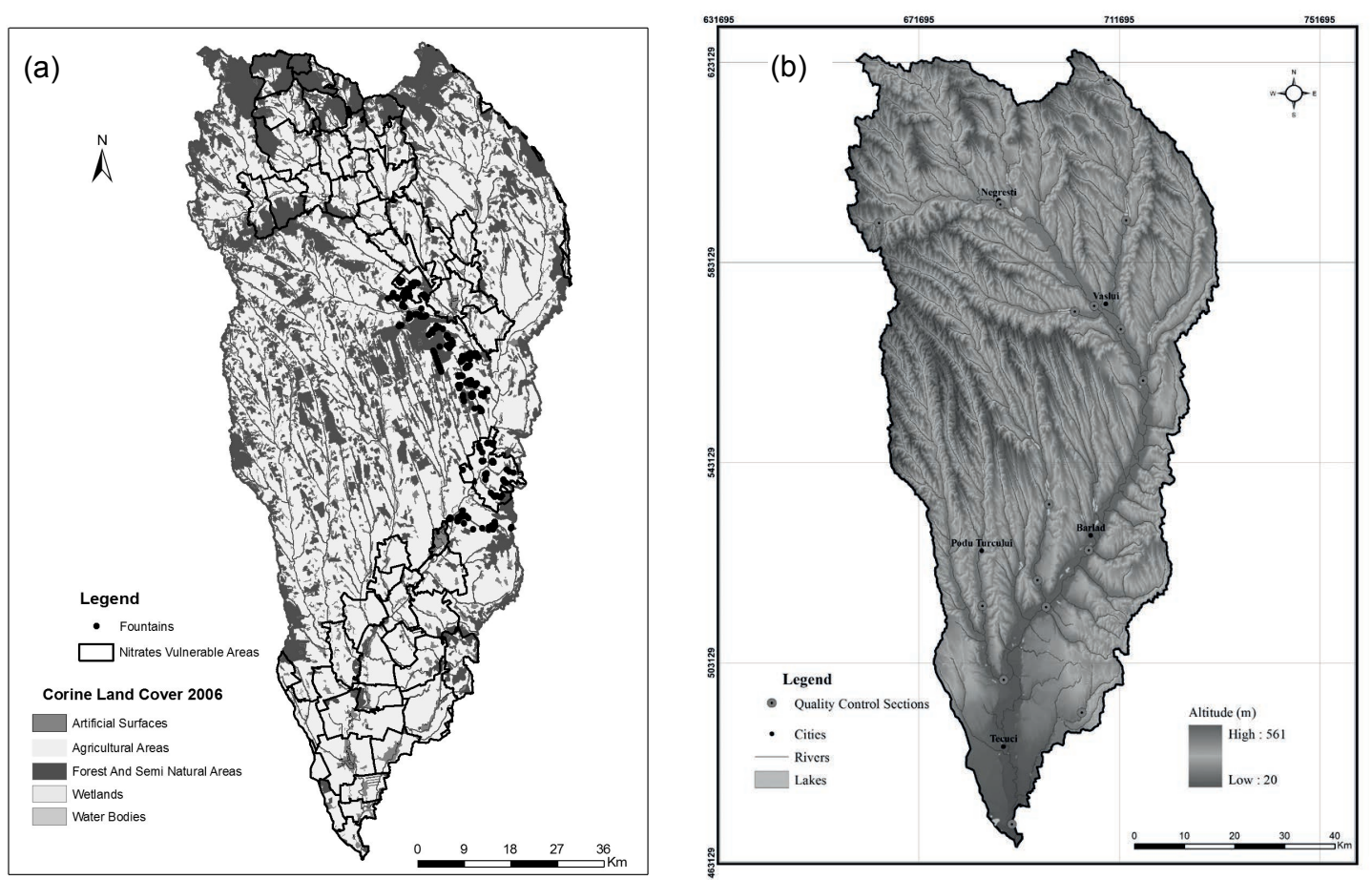

Fig. 2 Study area covered with portable sonde: domestic wells (a) and control sections from monitoring network (b) within the Barlad Basin.

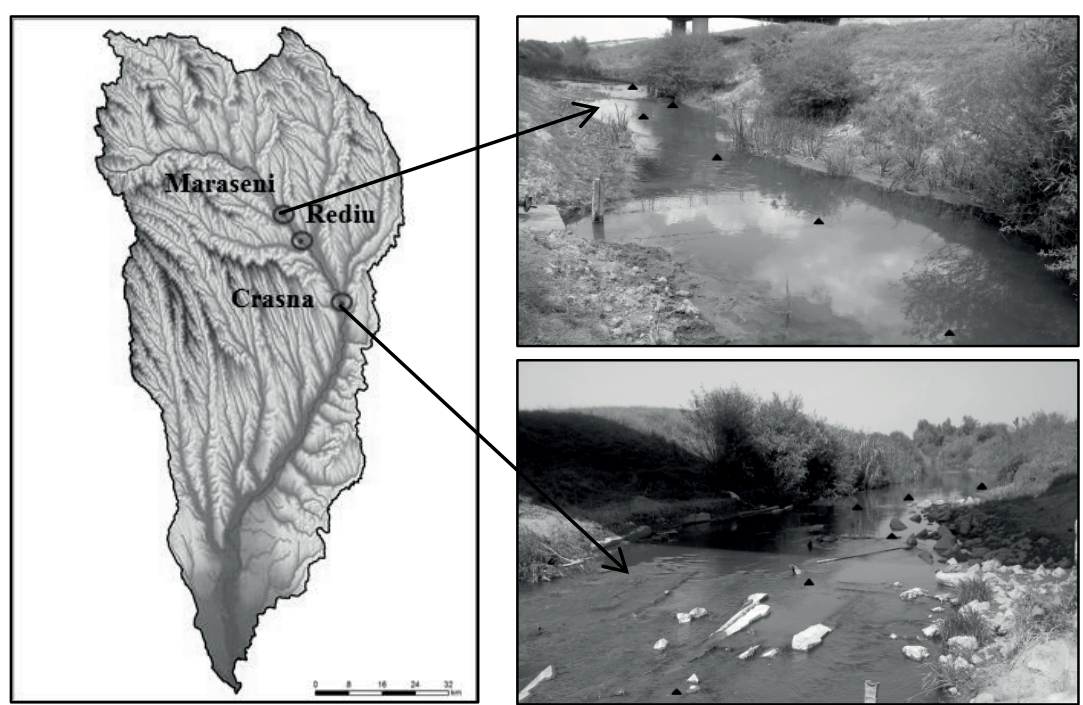

Fig. 3 Sampling sections for testing the portable sunder in different conditions, along the Barlad River ( $\boldsymbol{\Lambda}$, different sampling points).

More investigations about the sensibility of the mobile equipment, the conditions and the parameters of the river that influence the measured values have been done in summer months along the Barlad River (Fig. 3), in three control sections, located as follows: Maraseni-Rediu = $8 \mathrm{~km}$, Rediu - Crasna $=20 \mathrm{~km}$.

For each monitoring section, the measurements were done on a distance of $20-25 \mathrm{~m}$, in different sampling points (6-16 points) such as: along the main axis, near the river borders, in front of obstacles (e.g. stones), in areas with or without vegetation (e.g. macrophytes), under the bridge, in an area with high turbulence, or in an area with low flow. During the summer period the Barlad River was characterized by low flow and low water level. In order to avoid unsettling the water, we have measured from downstream to upstream, very slowly introducing the equipment into the water. 


\section{RESULTS AND DISCUSSION}

Taking into account that within the Barlad Basin there are no historical measurements for chlorophyll $a$ along the river, the field campaigns for surface water were focused on the values of chlorophyll $a$ and nitrate concentrations.

The results of the sampling campaigns indicated a good correlation between in situ monitoring and laboratory analysis (Fig. 4). Within sampling campaigns, linear curves were obtained for water temperature, $\mathrm{pH}$ and oxygen with $\mathrm{R} 2$ of $0.90,0.85$ and 0.91 , respectively. A comparison of results obtained in laboratory measurements and using the portable sonde, for nitrates and chlorophyll $a$, are shown in Fig. 5 for the Negresti control section, situated in the upstream part of the basin. Linear curves were obtained for both parameters in all control sections, with $\mathrm{R}^{2}$ between 0.70 and 0.86 .
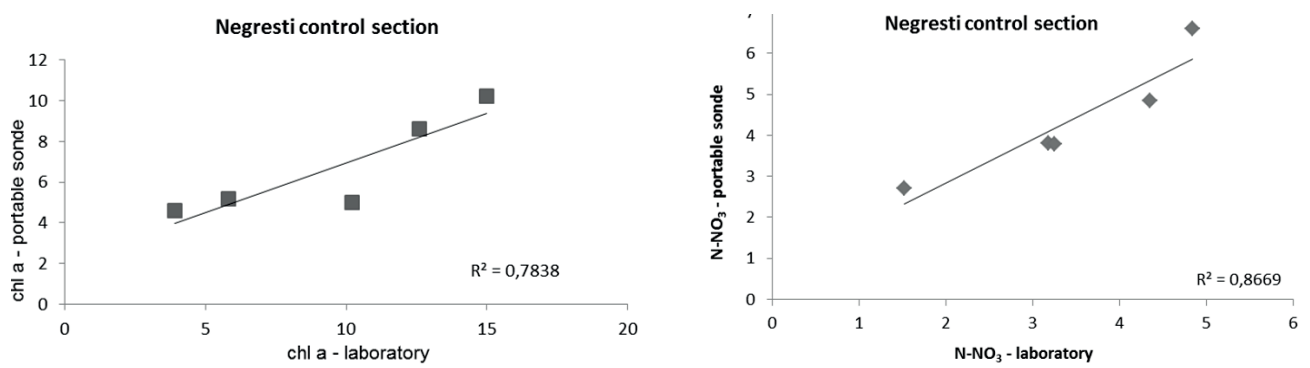

Fig. 4 Comparison of results for chlorophyll $a(\mu \mathrm{g} / \mathrm{L})$ and nitrates $(\mathrm{mg} / \mathrm{L})$ obtained in laboratory measurements and using portable sonde for the Negresti control section
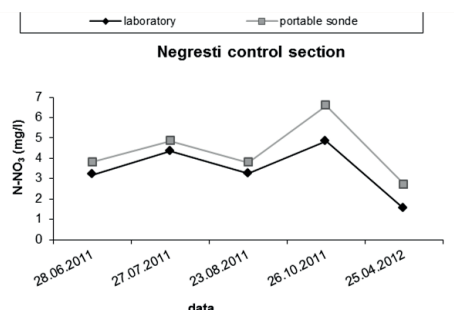

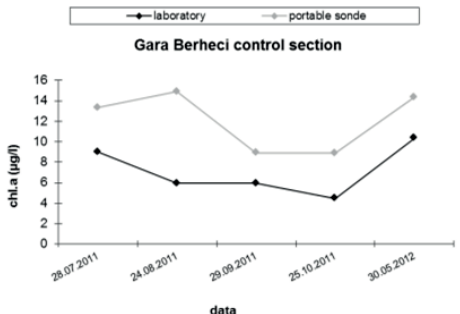

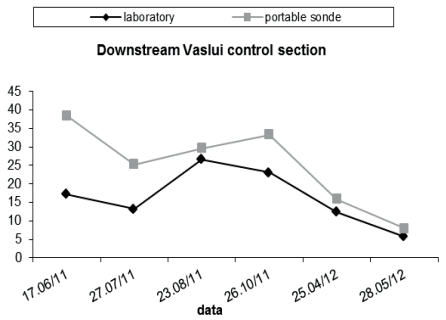

Fig. 5 Comparison between laboratory analysis and portable sonde measurements in different control sections along the Barlad main axis, for $\mathrm{N}^{-\mathrm{NO}_{3}}$, chlorophyll $a$ and $\mathrm{N}-\mathrm{NH}_{4}$ concentrations.

Most of the time, the values obtained directly in situ are higher than those obtained through laboratory analysis, due to the fact that the portable sonde is usually used for prevention activities rather than for the investigations activities about the source of pollution phenomena (Fig. 5). In a susceptible polluted area, the portable sonde can very quickly provide the pollutant concentration values, establishing if a detailed investigation though laboratory analysis is necessary.

The direct in situ measurements in the surface water have allowed for a much better picture of the true changes and extent of water pollution. For chlorophyll $a$, the concentrations increase from May, especially in the middle part of the basin where the values are higher than $50 \mu \mathrm{g} / \mathrm{L}$. For the nitrate concentrations. the results of field campaigns showed that: (i) there is a nitrogen pollution (nitrate and ammonium) in the basin; (ii) the contribution of Barlad basin to the nitrate pollution of Siret River basin is very low due to the fact that there is a great retention of nitrates within the basin.

Regarding the groundwater pollution, the measurements with the portable sonde in the domestic wells (fountains) have shown that the highest values (values greater than the maximum contaminant level, $50 \mathrm{mg} / \mathrm{L}$, for nitrates in drinking water) are recorded more in the neighbourhood of inside the villages, than in the agricultural and pasture areas situated between localities.

The water quality portable devices are ideal for groundwater and surface water monitoring, for research and assessment, but we must very carefully identify the sampling location. Within the three sampling campaigns (Fig. 3), we have analysed the factors that can influence the measurements of a multi-parameter sonde. So, we have done measurements in different points in the same cross-section profile, near the river border and near the main axis. Measurements show 
that the chlorophyll $a$ and oxygen concentrations are smaller near the river border than in the middle of the river, where there is high flow velocity and significant aeration. In the sampling points near the macrophytes vegetation, along the river border, the measurements show that the concentrations of chlorophyll $a$ are greater than in the area without vegetation, with mud and small water level. The values of nitrates and ammonium concentrations were higher due to the settlement of sediments and mud in areas with low flow or stagnant water, which generally favour the retention of nutrients. In the locations with low water level the portable sonde was very close to the bottom of the river, increasing the values of nitrates. Within the sampling campaigns, for the same sampling section, we have obtained a relative error of measurements of $0.1-2 \%$ for $\mathrm{pH}$ and water temperature, $1-8 \%$ for nitrates and $8-11 \%$ for oxygen and chlorophyll $a$.

Using the portable sonde we can cover a large surveyed area in a short time due to the fact that it can be used in more water quality control sections, along the river reach or even within the river basin. The differences between the laboratory analysis and portable equipment measurements are due to river parameters or to several phenomena that occurred during the field campaigns and attention should be paid to: (i) the sonde introduction in water, in order to avoid disturbing water and the sediment entrainment; (ii) the water level of the sampling point, in order to avoid touching the bottom of river where the sediments retain the nutrients; (iii) the selection of sampling points in order to avoid the stagnant water; (iv) the choice of period of time for sampling, in order to avoid the days immediately after raining period when the river's turbulence is higher; and (v) the cleaning / observation of portable sonde before measurement, in order to avoid the deposit of suspensions or different floating objects between the sampling points, gives wrong results.

\section{CONCLUSION}

Water sampling and laboratory analysis are still the most widely used tools for providing data, but due to its non-continuous nature, fixed monitoring and the delay in obtaining laboratory results, this method should be complemented by portable sonde measurements for prevention control. So in susceptible polluted areas the data sonde can very quickly provide the pollutants concentration values. We can easily establish if a detailed investigation is necessary, i.e. laboratory analysis and for what type of quality parameter. The speed of this method immediately offers solutions concerning the pollution prevention and later orientation, in an efficient way of the laboratory monitoring network.

Acknowledgements The financial support from European Community Commission, General Direction for Environment, in the framework of LIFE+ Program and the Romanian Government through the Ministry of Environment is gratefully acknowledged.

\section{REFERENCES}

Breabăn I. G. and Paiu M. (2012) The impact of anthropogenic nutrients on groundwater nitrate concentration in the Barlad area. Analele Universităţii din Oradea, Fascicula Protecţia Mediului XIX, 615-620.

Dascalita D. (2011) Integrated water monitoring system applied by Siret River Basin administration from Romania, important mechanism for the protection of water resources. Present Environment and Sustainable Development 5(2), 45-60.

Mihajlovic I, et al. (2013) S::can spectro::lyser - useful tool for monitoring of wastewater, the 6th PSU-UNS International Conference on Engineering and Technology (ICET-2013), no. T.2-2.2, 1-3

Macaleț R. and Dragusin D. (2008) Qualitative Status Analysis of the Phreatic Aquifer in the Barlad River Flood Plain concerning the Nitrogen-Based Compounds. In: Proceeding. Conference of Water Observation and Information System for Decision Support, 184-195.

Trifu M. C. (2002) Nutrients transfer in the Danube basin and contributions to the Black Sea: modeling and budget. Ph. D. Thesis, Université Pierre et Marie Curie Paris VI, pp: 145 (unpublished).

Trifu M. C., et al. (2011) Integrated system for protect and analyse the status and trends of water threatened by nitrogen pollution - LIFE09 ENV/RO/000612, available from www.lifecleanwater.ro.

Trifu M. C., et al. (2011) Identification of waters under nitrates pollutions threat using modeling approach in open-GIS environment In: International Multidisciplinary Scientific GeoConference SGEM, Modern Management of Mine Producing, Geology and Environmental Protection, ISSN 1314-2704, DOI: 10.5593/sgem2011.

Trifu M. C., et al. (2012) Geo-spatial analysis of the nitrate contamination of groundwater from diffuse sources. In: 21 st Century Watershed Technology: Improving Water Quality and the Environment Conference Proceedings. American Society of Agricultural and Biological Engineers, 12-13858.

Tuna G, Arkoc O, and Gulez K (2013) Continuous monitoring of water quality using portable and low-cost approaches. International Journal of Distributed Sensor Networks. http://dx.doi.org/10.1155/2013/249598, article ID 249598. 